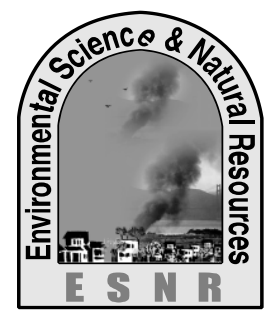

\title{
Preparation and Characterization of White Carbon Black From Rice Husk
}

\author{
M. A. A. Khan ${ }^{1 *}$, M. S. Saha ${ }^{2}$, S. Sultana ${ }^{1}$ and A. N. Ahmed ${ }^{3}$ \\ ${ }^{1}$ Institute of Glass and Ceramic Research and Testing, BCSIR, Dhaka-1205 \\ ${ }^{2}$ Institute of Mining, Mineralogy and Metallurgy, BCSIR, Joypurhat-6900 \\ ${ }^{3}$ Pilot Plant and Process Development Center, BCSIR, Dhaka-1205 \\ *Corresponding author: mdaa_khan@yahoo.com
}

\begin{abstract}
Generally white carbon black in a form of silica is used instead of carbon black as reinforcing filler for rubber compounding. In the present research white carbon black was prepared from rice husks in cost effective method with direct incineration of acid leaching rice husk. The physico-chemical properties of rice husk and the product of white carbon black obtained from rice husk were investigated by Thermogravimetry, Particle size analyzer, Scanning electron microscope; Fourier transformed infrared radiation (FTIR), X-ray fluorescence and X-ray difractometry analyses. It was found that the decomposition of organic constituents of rice husk was revealed by Thermo gravimetric and carbon, hydrogen, nitrogen, sulpher (CHNS) analyses. The FTIR spectrum showed presence of Si-O-Si band with a strong peak at $1085 \mathrm{~cm}^{-1}$. The analysis of particle size and scanning electron microscope demonstrated that the produced white carbon black represent different size of $112 \mu \mathrm{m}$ to $0.01 \mu \mathrm{m}$ with very small nano-particle and amorphous structure. The amorphous structure of product was also confirmed by XRD pattern. The high pure product as $99.9 \%$ was confirmed by XRF analysis. These types of product have potential application as filler in rubber compounding.
\end{abstract}

Key words: Amorphous silica, Rice husk, Silica and White carbon black

\section{Introduction}

Rice Husk (RH) is the outer layer of rice grain, which is the waste product of the rice milling process (Rohani et al., 2015). Various utilization of RH have been reported, but mostly it is used an alternative fuel for energy production, production of activated carbon and as a raw material for manufacture of industrial chemicals based on silica and silica compounds (Chungsangunsit et al., 2010; Kumar et al., 2012; Ghosh and Bhattacherjee, 2013). Silica and silica powder obtained from $\mathrm{RH}$ have much potential application in many industrially important products. White carbon black (WCB) is one of the applicable products of $\mathrm{RH}$. WCB is a form of silica $\left(\mathrm{SiO}_{2} \cdot \mathrm{nH}_{2} \mathrm{O}\right)$ that is used instead of carbon black mainly in rubber compounding. The product is very finely divided and reactive. It is mainly use as a catalyst, catalyst carrier, decolorizer, delustering agent, reinforcing agent for rubber, filling agent for plastics, thickening agent for printing ink, softness polishing agent for metal, filler for insulation and heat insulation, and filler for advanced cosmetics and spraying materials (Kejing et al., 2013). It is an industrial gourmet powder for improving the quality of products in rubber. However the utilization of WCB depends on the quality and particle size of the product. For example the product size about 30 to 50 $\mu \mathrm{m}$ can be used only in production of general rubber while the ultrafine products size less than $10 \mu \mathrm{m}$ can be used as a reinforcing agent in high-grade rubber products, because of their large specific surface area, strong linking ability, good dispersity, and good optic and mechanical properties.

In rubber compounding, fillers are major additives, because it enhances the tensile strength, modulus, tear strength, abrasion resistance, and stiffness of such properties of the product. Different material have been used as a filler to reinforce natural and synthetic rubber such as carbon black, clay, shale, synthetic and precipited amorphous white silica, recycled rubber powder, graphite (Ismail et al., 2002; Kim et al., 2003; Ansarifar et al., 2006; Yang et al., 2006; Pan et al., 2015). Agricultural by-products has also been used as a filler, this included banana peel, rice husk, spent mango, bean seed skin and groundnut shell (Adeosum, 2002); cocoa pod and rubber seed shell, ash of rice husk (Ismail et al., 2001) etc. In the vulcanization of rubber, usually carbon black used much more than that of others. The origin of carbon black from petroleum which causes pollution and gives rubber black and expensive (Isaac and Augustina, 2011), while the processing of agricultural by-product likes $\mathrm{RH}$ is flexible, economical and ecological.

In global context, annual rice husk production is about 137 million tones whereas Bangladesh produces about 9.0 million tons (FAOSTAT, 2011). Around 22\% of the paddy mass is husk and the major constituent of rice husk are hydrated silicon and organic materials consisting of $55-60 \mathrm{wt} \%$ of cellulose and hemicelluloses and $22 \mathrm{wt} \%$ of lignin. During the process about $20 \%$ mass of rice husk remains as ash and this contains $80-95 \%$ amorphous silica. Therefore, in the present study $\mathrm{RH}$ has been considered as a source of silica and this attempt has been made up for WCB production from RH. Several methods for preparing WCB from RH have been reported. But most of them are uneconomical and need huge energy. Moreover various research studies concerning the silica production and application of RH have already been made, but there are still contradictory regarding the optimum condition of production and its relationship with the properties of the final RH (Rosario et al., 2012). In this consensus, production of high reactive pure silica, some conditions are crucial in order to obtain an amorphous structure and the absence of unreactive carbon. This paper reports a comprehensive characterization of WCB produce from $\mathrm{RH}$ in cost effective method simply by burning under appropriate condition to achieve a good quality product. 


\section{Materials and Methods}

\section{Materials}

The raw material RH was collected in a nearby rice mill. All reagents used were analytical grade and purchased from local agent of Merck Germany Co. Ltd. Sample was prepared by proper washing and thermal treatment procedure and characterized by standard method.

\section{Preparation of $\mathrm{WCB}$}

The collected RH was washed thoroughly with clean tap water to remove the soluble particles, dust, and other contaminants present, whereby the heavy impurities such as sand was also removed. It was then dried in an air oven at about $60^{\circ} \mathrm{C}$ for $24 \mathrm{~h}$. The dried $\mathrm{RH}$ was grinded to made sieve size at $-45 \mu \mathrm{m} .100 \mathrm{~g}$ of fine grinding $\mathrm{RH}$ was mixed with $800 \mathrm{ml}$ of $10 \% \mathrm{HCl}$ and refluxed them for $3 \mathrm{~h}$ by stirring frequently. It was cooled and standby for about $20 \mathrm{~h}$. separated the residue by refrigerated centrifugation. Washed them with hot water and repeated the centrifugation until the residue became free from $\mathrm{HCl}$. The residue was made moisture free by oven drying at $100^{\circ} \mathrm{C}$. The treated husk was burnt in an electric furnace by controlling the temperature so that it reached $700^{\circ} \mathrm{C}$ in $1 \mathrm{~h}$ at heating rate $5^{\circ} \mathrm{C} / \mathrm{min}$ and continuing heating in additional $3 \mathrm{~h}$ at $700^{\circ} \mathrm{C}$. The desired product was obtained as a white powder.

\section{Analysis of RH and WCB Silica}

The silica and metallic impurities in the samples were analyzed by X-RF (model: Rigaku ZSX Primus, Japan). Particle size of the RH as well as product silica was measured by using a laser based particle size analyzer (model microtrac-S3500). Carbon, hydrogen, nitrogen and sulpher (CHNS) were measured by HEKAtech elemental analysis (model Euro EA-3000, Germany). The $\mathrm{O}_{\text {difference }}$ was calculated air dry and ash free basis. Fourier transforms infrared spectroscopy FTIR spectra were recorder with $\mathrm{KBr}$ pellets using a WQF-510 FTIR Rayleigh (Beijing Rayleigh Analytical Instruments CO. Ltd., Beijing, China). The $\mathrm{pH}$ was measured with a Jenway pH meter (model Jenway-3510, UK). Chemical phases were identified by X-ray diffractometer (XRD) (model Bruker-D8 Advance) using a $\mathrm{Cu}-\mathrm{K} \square$ radiation source $(\square=1.5406 \AA)$.

\section{Results and Discussion}

\section{Characterization of $\mathrm{RH}$}

RH mainly comprises with organic constituents as celluloses, hemicelluloses and lignin and the remaining residue contains silica with small amount of metallic oxides. Iyenagbe et al., 2012 reported the average composition of $\mathrm{RH}$ which is given in Table 1 . The amount of constituents of $\mathrm{RH}$ varies rice to rice as well as it depends on the rice variety, soil chemistry, climate condition and the geographic localization of the culture (Iyenagbe and Othman, 2012). On the other hand, a typical analysis results of experimental $\mathrm{RH}$ are shown in Table 2 which gives tremendous idea about silica and organic constituents as carbon, hydrogen, nitrogen, sulpher and oxygen difference of RH. Table 2 showed as-received moisture content of experimental $\mathrm{RH}$ was $8.5 \%$ and ash $19.32 \%$, which content desired product $\mathrm{SiO}_{2}$. The elemental analysis of $\mathrm{RH}$ showed $\mathrm{C}, \mathrm{H}, \mathrm{N}, \mathrm{S}$ was $33.48 \%, 4.66 \%, 0.59 \%$, and $0.04 \%$, respectively which indicated the high organic constituent's presents in $\mathrm{RH}$.

Table 1. Composition of RH

\begin{tabular}{|l|c|}
\hline \multicolumn{1}{|c|}{ Constituent } & Wt (\%) \\
\hline Celluse & 35 \\
\hline Hemicellulose & 25 \\
\hline Lignin & 20 \\
\hline Crude protein $(\mathrm{N} \times 6.25)$ & 3 \\
\hline Ash & 17 \\
\hline
\end{tabular}

The chemical composition of $\mathrm{RH}$ as-received and the $\mathrm{RH}$ treated with $10 \% \mathrm{HCl}$ and finally heated at $700^{\circ} \mathrm{C}$ at a rate of $10^{\circ} \mathrm{C} \min ^{-1}$ for $4 \mathrm{~h}$ was analyzed by X-RF. The resulting data has showed in Table-3, which demonstrated $90 \% \mathrm{SiO}_{2}$ present in as-received $\mathrm{RH}$, $93 \%$ present in $\mathrm{HCl}$ leaching $\mathrm{RH}$, while $99.9 \% \mathrm{SiO}_{2}$ was obtained by heating of $\mathrm{HCl}$ treated $\mathrm{RH}$. A traces of elements were found in an order $\mathrm{RH}$ (As- received)> $\mathrm{RH}(\mathrm{HCl}$ leaching)> $\mathrm{RH}$ (Heating of $\mathrm{HCl}$ treated $\mathrm{RH}$ ), which indicated that the heats with $\mathrm{HCl}$ treated $\mathrm{RH}$ gives high pure and high concentration of $\mathrm{SiO}_{2}$ than that of direct heating of as-received RH.

Table 2. Properties analysis of $\mathrm{RH}$

\begin{tabular}{|l|l|}
\hline Parameters & RH \\
\hline Moisture\% & 8.5 \\
\hline Ash\% & 19.32 \\
\hline $\mathrm{C} \%$ & 33.48 \\
\hline $\mathrm{H} \%$ & 4.66 \\
\hline $\mathrm{N} \%$ & 0.59 \\
\hline $\mathrm{S} \%$ & 0.04 \\
\hline $\mathrm{O}_{\text {diff. } \%}$ & 33.41 \\
\hline
\end{tabular}


Table 3. Chemical composition of $\mathrm{RH}$ with different condition

\begin{tabular}{|l|l|l|l|l|l|}
\hline \multirow{2}{*}{$\begin{array}{c}\text { Composition } \\
\text { (wt \%) }\end{array}$} & \multicolumn{2}{|c|}{$\begin{array}{c}\text { RH } \\
\text { (As received) }\end{array}$} & \multicolumn{2}{c|}{$\begin{array}{c}\text { RH } \\
\text { (HCl leaching) }\end{array}$} & $\begin{array}{c}\text { RH } \\
\text { After } \\
\text { burning) }\end{array}$ \\
\cline { 2 - 6 } & $\begin{array}{c}\text { Direct X-RF } \\
\text { analysis data }\end{array}$ & $\begin{array}{c}\text { Calculated } \\
\text { data on LOI }\end{array}$ & $\begin{array}{c}\text { Direct X-RF } \\
\text { analysis data }\end{array}$ & $\begin{array}{c}\text { Calculated } \\
\text { data on LOI }\end{array}$ & \\
\hline $\mathrm{SiO}_{2}$ & 84.35 & 11.60 & 93.73 & 16.57 & 99.90 \\
\hline $\mathrm{Al}_{2} \mathrm{O}_{3}$ & 2.33 & 0.32 & 0.22 & 0.038 & 0.04 \\
\hline $\mathrm{Cr}_{2} \mathrm{O}_{3}$ & 0.82 & 0.11 & 0.14 & 0.024 & 0.01 \\
\hline $\mathrm{CaO}$ & 2.83 & 0.39 & 1.20 & 0.212 & 0.02 \\
\hline $\mathrm{SO}_{3}$ & 0.26 & 0.045 & 0.17 & 0.030 & - \\
\hline $\mathrm{Fe}_{2} \mathrm{O}_{3}$ & 2.63 & 0.36 & 0.70 & 0.123 & 0.02 \\
\hline $\mathrm{K}_{2} \mathrm{O}$ & 2.36 & 0.32 & 0.20 & 0.035 & 0.01 \\
\hline $\mathrm{ZnO}$ & 0.04 & 0.005 & 0.08 & 0.014 & - \\
\hline $\mathrm{MgO}$ & 1.71 & 0.23 & - & & - \\
\hline $\mathrm{MnO}$ & 0.27 & 0.037 & - & & - \\
\hline $\mathrm{Rb} \mathrm{b}_{2} \mathrm{O}$ & 0.03 & 0.004 & - & & - \\
\hline $\mathrm{NiO}$ & 0.07 & 0.012 & - & & - \\
\hline $\mathrm{CuO}$ & 0.01 & 0.0017 & - & & - \\
\hline $\mathrm{TiO}_{2}$ & 0.14 & 0.024 & - & & - \\
\hline $\mathrm{Na}_{2} \mathrm{O}$ & 0.21 & 0.037 & - & & \\
\hline $\mathrm{P}_{2} \mathrm{O}_{5}$ & 1.94 & 0.344 & & & ND \\
\hline $\mathrm{LOI}$ & - & 86.24 & - & & \\
\hline
\end{tabular}

\section{Thermogravimetric (TG) analysis of $\mathrm{RH}$}

TG analysis was used to determine the existence of organic components in the RH. The TG curves of RH are shown in Fig. 1. This showed initial weight loss occurs within the range of $0-100^{\circ} \mathrm{C}$ with a weight loss of about $2-5 \%$ correspondence to loss of water and other volatile substances. The second stage revels a rapid and large weight loss at temperature between 150 $-350^{\circ} \mathrm{C}$ and gives $40-50 \%$ weight loss. This is due to the thermal decomposition of hemicelluloses and cellulose as a major organic component in the RH. Because hemicelluloses decompose mainly at $150-350^{\circ} \mathrm{C}$ while cellulose at $275-350^{\circ} \mathrm{C}$ reported elsewhere (Shafizadeh et al., 1976; Antal, 1983). The third stage showed a weight loss of about $25 \%$ that could be due to lignin, a thermally more stable aromatic polymer which undergoes gradual decomposition between $350-750^{\circ} \mathrm{C}$. The residual of ash is mainly the non-combustible silica.

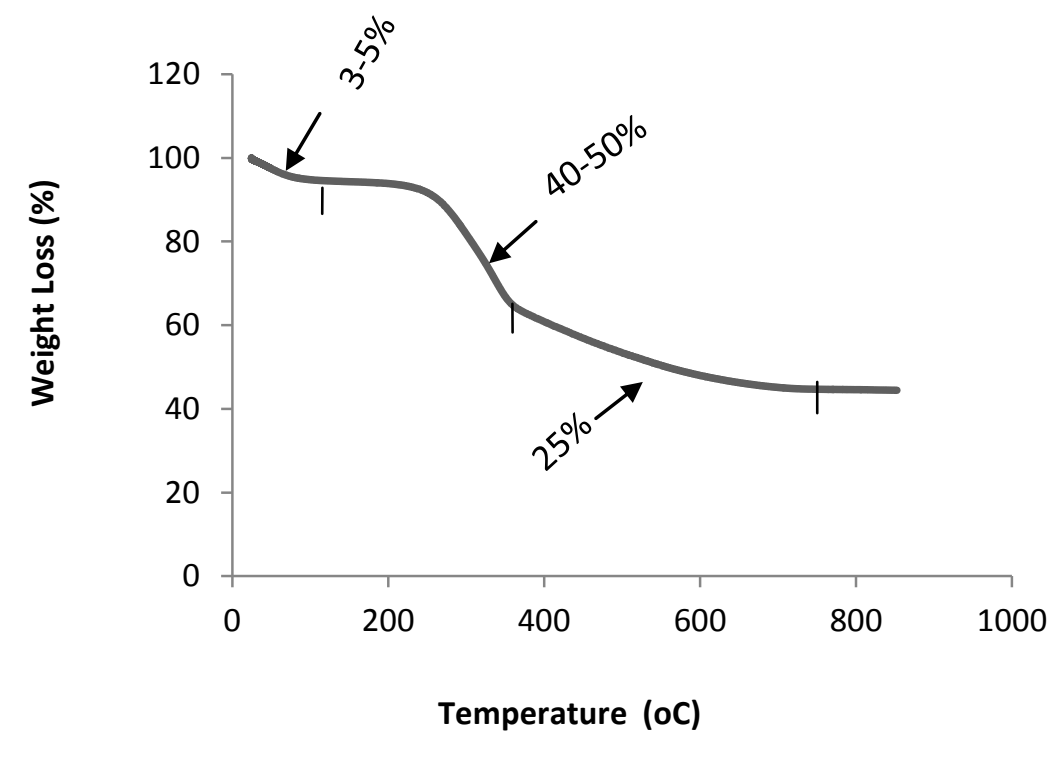

Fig. 1. Thermo gravimetric (TG) curves of RH 


\section{FT-IR analysis of RH and WCB}

FTIR spectrum of WCB are shown in Fig. 2. In this figure the peaks at $1,116 \mathrm{~cm}^{-1}$ and $845 \mathrm{~cm}^{-1}$ are due to $\mathrm{Si}-\mathrm{O}-\mathrm{Si}$ asymmetric and symmetric stretching modes, respectively. Typical bands of product WCB shows OSi-O stretching at $1085 \mathrm{~cm}^{-1}, 1167 \mathrm{~cm}^{-1}$ and $845 \mathrm{~cm}^{-1}$ and bending vibrations at $610 \mathrm{~cm}^{-1}$. A broad band's at $3450-3600 \mathrm{~cm}^{-1}$ and a band at $1733 \mathrm{~cm}^{-1}$ corresponded to the $\mathrm{O}-\mathrm{H}$ stretching and bending vibrations. The band centered at $610 \mathrm{~cm}^{-1}$ is due to the bending frequency of
Si-O-Si. A large broad band around $3600 \mathrm{~cm}^{-1}$ was attributed to the presence of the $\mathrm{O}-\mathrm{H}$ stretching frequency for the silanol group and the remaining adsorbed water. A band around $1733 \mathrm{~cm}^{-1}$ was assigned to the bending vibration of water molecules bound to the silica matrix. The FTIR spectra show $\mathrm{C}-\mathrm{H}$ peaks at $2880 \mathrm{~cm}^{-1}$ and $2955 \mathrm{~cm}^{-1}$, clearly indicating the organic modification of the nanoparticle surface and the silica nanoparticle obtained in amorphous state.

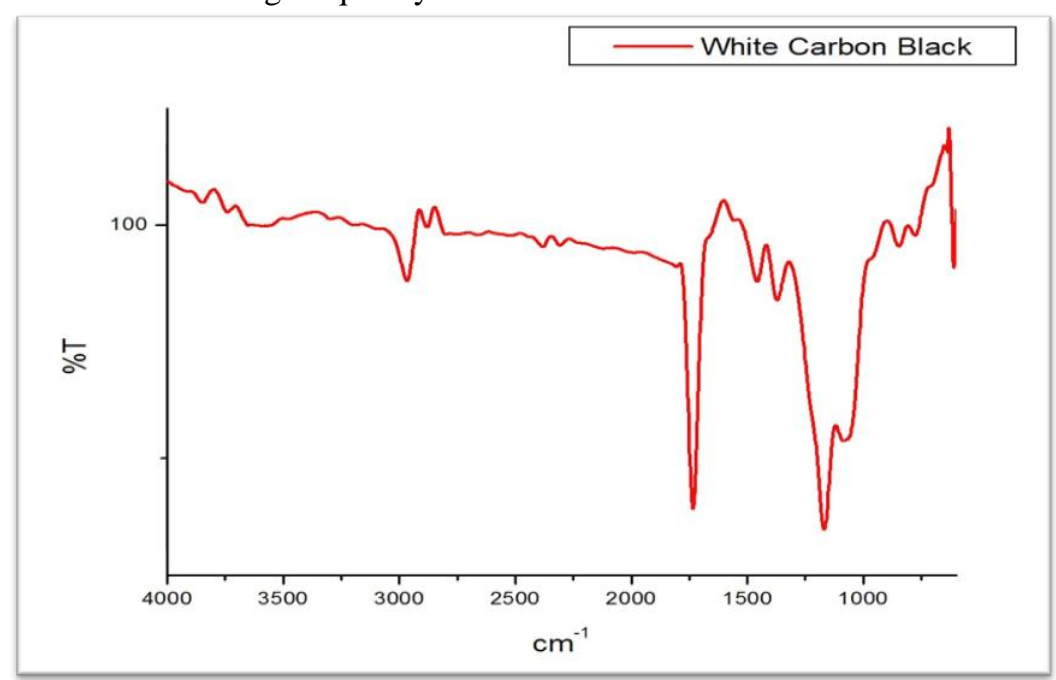

Fig. 2. FTIR pattern of WCB

\section{Particle size analysis of $\mathrm{WCB}$}

The particles of the product WCB are not equal in size. As shown in Fig. 3 the maximum size of particle was observed $112 \mu \mathrm{m}$, while minimum was $0.01 \mu \mathrm{m}$ and showed high concentration than that of maximum size.
The specific surface area was shown $115.8 \mathrm{~m}^{2} \mathrm{~kg}$. These findings indicate that the particles of silica were agglomerates of small nano range particles and forming globules platelets of varied sizes.

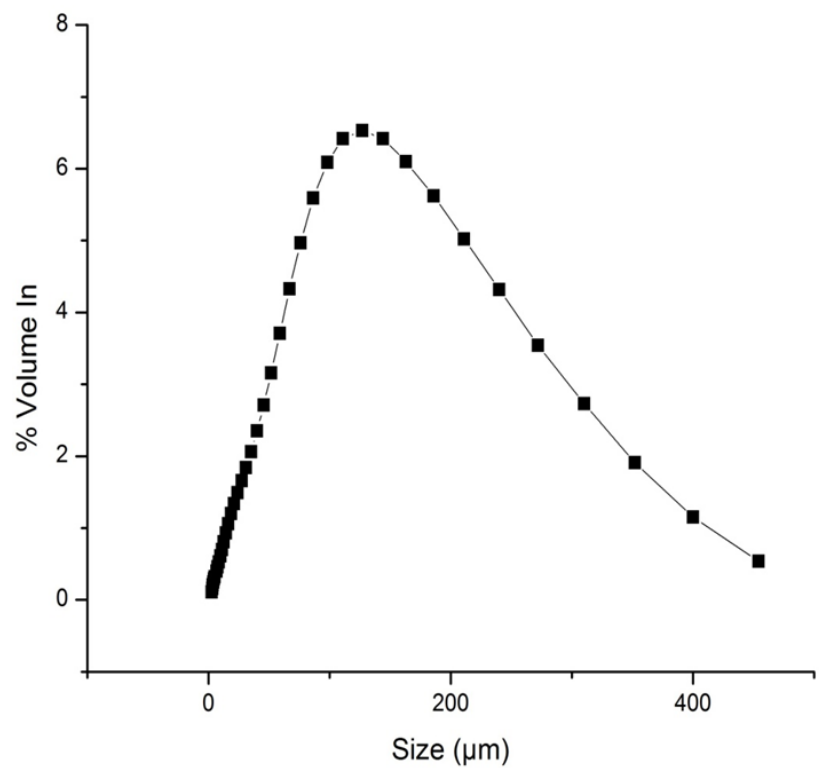

Fig. 3. Particle size distribution of WCB

\section{SEM-EDAX analysis}

The morphological structure as well as atomic wt $\%$ of prepared WCB was analyzed by SEM-EDAX which is shown in Fig. 4. Generally silica which is formed by incinerating rice husk above $800^{\circ} \mathrm{C}$ is crystal (Kalapathy et al., 2002; Olamide and Oyawale, 2012). In the present research silica was obtained as WCB by heating at $700^{\circ} \mathrm{C}$. So the morphological features of the 
amorphous silica were observed in Fig. 4.a. as cluster form and/or fine globules and/or platelets with multifaceted particle shape and size. It seems that particle of silica are agglomerates of small nano-range particle. Atomic wt $\%$ of the elements of silica cluster was measured from the spot-004 as shown in Fig. 4.b and summarized in Fig. 4.c. Which showed atomic wt\% of $\mathrm{Si}$ and $\mathrm{O}$ were $53.35 \%$ and $46.55 \%$, respectively, indicating the WCB as silica obtained from rice husk was $99.9 \%$ pure.

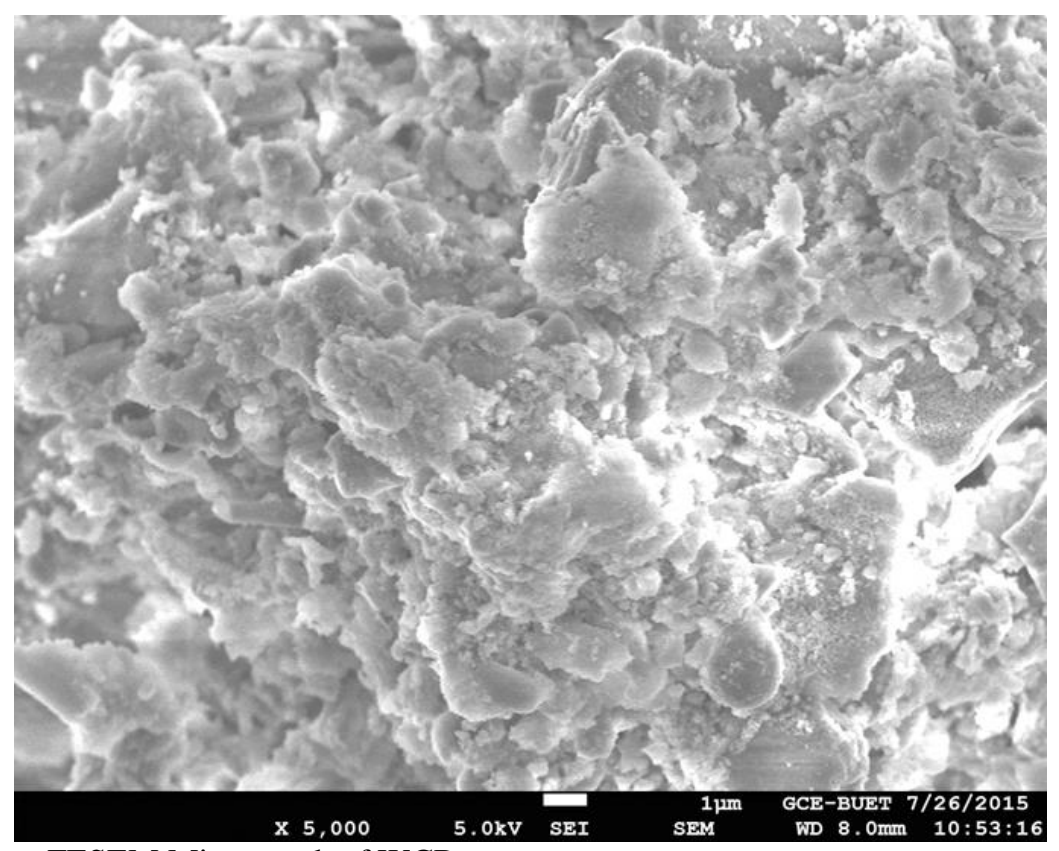

a. FESEM Micrograph of WCB

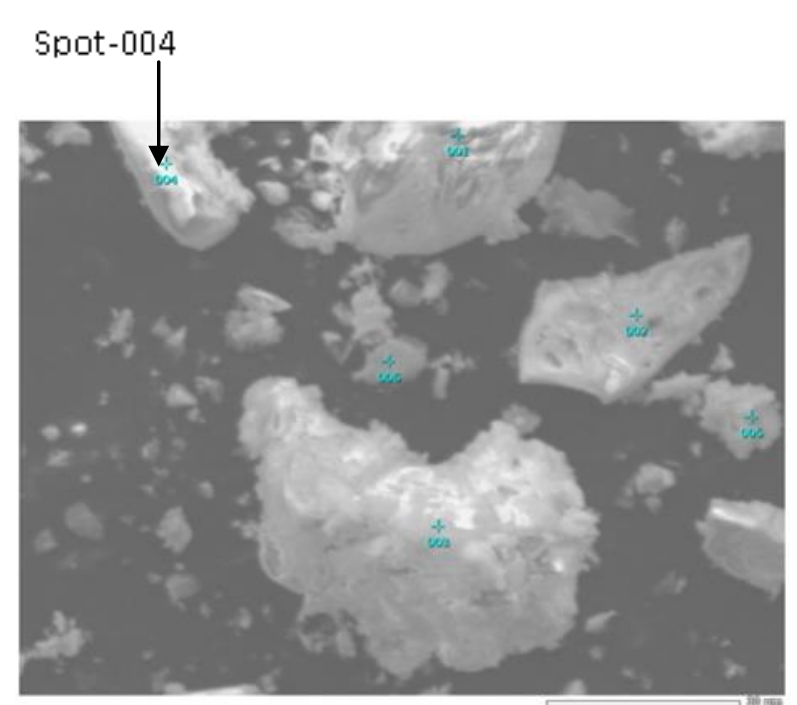

b. EDAX of WCB Spot- 004

\begin{tabular}{|c|c|}
\hline Element & Atomic\% \\
\hline $\mathrm{O}$ & 46.55 \\
\hline $\mathrm{Al}$ & - \\
\hline $\mathrm{Si}$ & 53.35 \\
\hline $\mathrm{K}$ & 0.02 \\
\hline $\mathrm{Ca}$ & - \\
\hline $\mathrm{Cr}$ & - \\
\hline $\mathrm{Fe}$ & - \\
\hline $\mathrm{Zn}$ & 0.08 \\
\hline & 100 \\
\hline
\end{tabular}

c. EDAX analysis of WCB

Fig. 4. SEM-EDAX photograph: a) FESEM Micrograph of WCB. b) EDAX of WCB Spot- 004. c) EDAX analysis of WCB

\section{XRD analysis}

The phase identification of desired product WCB was assessed by XRD in Fig. 5. The pattern showed a broad peak at $2 \theta=22^{\circ}$ and no defined sharp peaks due to crystalline were encountered, confirming the results from the silica activity index allowed to conclude that the silica produced from $\mathrm{RH}$ has an amorphous structure. 


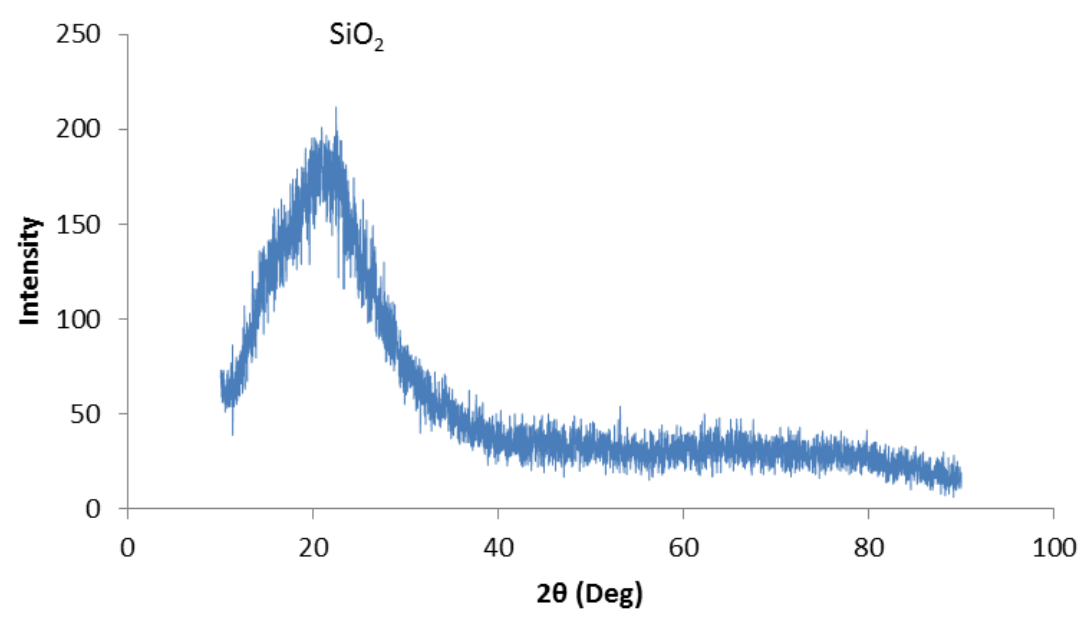

Fig. 5. XRD pattern of WCB

\section{Conclusions}

In the present study, WCB was prepared by direct incineration of acid leaching $\mathrm{RH}$ with optimum heating condition at $700^{\circ} \mathrm{C}$ for $4 \mathrm{~h}$ at $5^{\circ} \mathrm{Cmin}^{-1}$ heating rate. The product was conducted with different experiments for characterization. The experimental results showed that the prepared WCB was amorphous in structure with nano and/or micro level particle in size and $99.9 \%$ pure with large surface area. These might be useful as filler for plastic and rubber compounding.

\section{Acknowledgement}

We acknowledge Bangladesh Council of Scientific and Industrial Research (BCSIR), Ministry of Science Technology, Govt. of Bangladesh for financial support.

\section{References}

Ansarifar, A.; Shiah, S. F. and Bennett, M. 2006. Optimizing the chemical bonding between silanised silica nanofiller and natural rubber and assessing its effects on the properties of the rubber. International Journal of Adhesion and adhesives, 60: 454-463.

Anatal, M. J. 1983. Biomass pyrolysis: a review of the literature. Part 1- carbohydrate pyrolysis. Advances in Solar Energy, 11: 61-111.

Chungsangunsit, T.; Gheewala, S. H. and Patumsawad, S. 2010. Emission Assessment of rice huskcombustion for power production. International Journal of Civil and Environmental Engineering, 2: 185-190.

FAOSTAT. 2011 http://faostat.fao org/site/339/default.aspx accessed on 20-08-2011.

Ghosh, R. and Bhattacherjee, S. A. 2013. A review study on precipitated silica and activated carbon from rice husk. Journal of Chemical Engineering Process and Technology, 4: 1- 4.

Ismail, H.; Nordin, R. and Noor, A. M. 2002. Cure characteristics, tensile properties and swelling behavior of recycled rubber powder-filled natural rubber compounds. Polymer Testing, 21(4): 565569.

Isaac, O. I. and Augustina, A. E. 2011. Studies on mechanical and end-use properties of natural rubber filled with snail shell powder. Materials Sciences and application, 2: 802-810.

Iyenagbe, B. U. and Othman, M. 2012. A critical assessment and new research directions of rice husk silica processing methods and properties. Maejo Int. J. Sci. Technol., 6(3): 430-448.

Kumar, A.; Mohanta, K.; Kumer, D. and Prakash, D. 2012. Properties of industrial applications of rice husk. A Review of International Journal of Engineering Technology and Advanced Engineering, 2: 86-90.

Kejing, X.; Qingwen, S.; Yanqing, G.; Yingving, Z. and Shuhua, D. 2013. Preparation of superhydrophobic white carbon black from nano-rice husk ash. Res. Chem. Intermed., DOI 10.1007/s 11164-013.1094-3.

Kim, M.; Kim, D.; Chowdhury, S. R. and Kim, G. 2003. Melt-compounded butadiene rubber nanocomposites with improved mechanical properties and abrasion resistance. Journal of Applied Polymer Science, 102(3): 2062-2066.

Kalapathy, U.; Procto, A. and Shultz, J. 2002. A simple method for production of pure silica from rice hull ash. Bioresource Technology, 73: 257-262.

Olamide, O. and Oyawale, F. 2012. Characterization of rice husk via atomic absorption spectrophotometer for optimal silica production, 2: 4-4.

Pan, J. Z.; Tan, L. F.; Fan, X. and Han, M. 2015. Effect of carbon black reinforcing fillers on mechanical properties of NBR materials used for the progressing cavity pump. Applied Mechanics and Materials, 750: 339-344.

Rosario, M.; Nogueira, C. A. and Margarido, F. 2012. Production and characterization of amorphous silica from rice husk waste. International Conference on 
Engineering for waste and Biomass Valorization, Porto, Portugal.

Rohani, A. B.; Rosiyah, Y. and Seng, N. G. 2015. Production of high purity amorphous silica from rice husk. Procedia Chemistry, 19: 189-195.
Shafizadeh, F. and DeGroot, W. F. 1976. Combustion characterization of cellulosic fuels. New York Academic Press, 1-18.

Yang, J.; Tian, M. M.; Jia, Q.; Zhang, L. and Li, X. 2006. Influence of graphite particle size and shape on the properties of NBR. Journal of Applied Polymer Science, 102(4): 4007-4015. 